\title{
Study on the Competency of Bilingual Art Teachers Based on the Psychology Capital Intervention Model
}

\author{
Donglan $\mathrm{Li}^{1}$ \\ ${ }^{1}$ School of Art, Guangdong University of Foreign Studies, Guangzhou, China \\ Correspondence: Donglan Li, female, Associate Professor, School of Art, Guangdong University of Foreign \\ Studies, Da Xue Chen campus, Guangzhou City, 510006, Guangzhou, China. E-mail: dong19621218@126.com
}

Received: August 18, 2013

Accepted: September 2, $2013 \quad$ Online Published: November 12, 2013

doi:10.5539/jel.v2n4p40

URL: http://dx.doi.org/10.5539/jel.v2n4p40

\begin{abstract}
In this globalization era, it is an important strategy to focus on the core status of bilingual art teachers in the internationalization of higher education. And it is necessary to prepare a thorough, detailed, well-designed assessment criterion for teachers, especially for teachers specialized in art, as their competency relates directly to whether the fine art culture can be inherited and whether the cultural communication can be achieved. Based on the positive psychological capital of students majoring in art, this research investigates art teachers' bilingual teaching attitude, and how to construct the competency of art teachers via bilingual teaching.
\end{abstract}

Keywords: psychological capital, bilingual teacher, competency, intervention model

\section{Research Background}

Educational modernization and internationalization are two megatrends of education development in the world. The internationalization of higher education presages of a possibility that the open-ended, innovative, quality-oriented education will become the basic trend of higher education, which requires teachers to evolve in their roles, from the tutor of students acquiring knowledge into their designer of the future life. As the implementation of the National Medium-term or Long-term Program of Development for Education goes further and further, the deterioration of the problems arising from the process of education internationalization also speeds up day by day on both dimensions of depth and breadth. On the micro level, the study of education internationalization mostly focuses on bilingual education. Ever since the Ministry of Education of People's Republic of China issued A Number of Opinions on Strengthening Undergraduate Teaching of Higher Education and Enhancing Education Quality, documents like Opinions on the Implementation of Undergraduate Teaching Quality and Reform Project in Higher Education have been published in succession to encourage colleges and universities "to proactively hire foreign scholars and experts to engage in the teaching of professional courses in bilingual manner, and to encourage or support overseas graduates to return and to teach professional courses in English, eventually to enhance undergraduate students' English competency for special academic purposes." The nation has also approved of 403 courses as Bilingual Teaching Demonstration Courses. It vigorously pursues bilingual education not only to enhance students' English skills, but also to hope that college or university students can master the most updated knowledge in their majors and reach the cutting-edge of the specialized science and technology. Speaking of further objectives, one, among others, is to enhance the self-confidence of students via bilingual learning and to help them obtain inner peace and ability to hold hopes and positive expectations for the future. As a result, they will be able to deal with the complicated international competition and to improve the international competitiveness of our country's higher education. And the core personnel in charge of cultivating the positive psychological capital of students is the teachers working in the forefront of colleges and universities. Their sense of identity with the bilingual teaching and their competency in the teaching methods take the pivotal role here.

This article attempts to study the attitudes and methods employed by art teachers based on the model of the students' positive psychological capital. As for students of art majors, the talented ones in this field feel the pressing urge of internationalization. Art teachers' attitudes towards or ideas of internationalization and their international knowledge, experience and methods will directly influence the planning and implementing of the art courses' international strategy. Their competency is in direct relation to the inheritance of the fine art culture as well as the realization of the cultural communication. Not only should art talents acquire adequate 
professional skills and be familiar with different kinds of knowledge, such as vocal music; but also they should understand multi-cultures in various countries and achieve favorable psychological capital. Professional knowledge is the footstone of nurturing art talents, but cultivating art talents' understanding, assimilation and accumulation of different cultures, and their favorable psychological capital is the key to securing their capability of expressing their Chinese elements on the international stage.

For students majoring in art, the bilingual education of the students possesses features which are different from that of other majors. Students majoring in art have primarily three kinds of particularities as follows. Firstly, students who are from school of art usually obtain poor overall academic records, and lack bilingual skills, especially English skills. This has something to do with the enrollment sources of this group of students. Quite a lot of art students are just persuaded by their parents to learn art because of their bad academic performance in school. Though some students have strong interest in learning art, they have little incentive to learn other subjects, such as English, which brings difficulty to the bilingual teaching. Secondly, students majoring in art have a tendency to emphasize personality, which results in management difficulty. Art students tend to be brisk and lyrical, and accordingly, their personal characteristics differ from those of their counterparts in other majors. Thirdly, it seems that art students have more opportunities to take part in competitive events, asking for more personal space and having more motivations to learn art and to pursue artistic creation. They belong to a special group of people, among which rigid doctrine and lecturing will easily arouse dislike and aversion. Teachers of school of art, especially those teaching students majoring in art, on the other hand, have intense value orientation of self-expression and self-improvement, and strong personality. Under this circumstance, students and teachers involving in bilingual teaching form an oneness made up of opposites.

\section{Introduction of Competency Theory}

After David·McClelland in Harvard formally raised the concept of competency, McClelland and Spencer improved the concept of 'competency' and divided it into basic competency, differentiating competency and transformative \& development competency. Basic competency is the basic requirement of the position, differentiating competency is the key condition to the position, and transformative \& development competency refers to the unique characteristics or traits of the occupant, namely the characteristics difficult to be simulated or exceeded by others, which also represents unique competency and some subjective content like motivation, specialty, value and cognition of the achiever. Generally speaking, competencies have characteristics of comprehensiveness, identifiability and dynamics.

According to relevant statistics, teachers taking charge of bilingual teaching usually possess better abilities. Both their qualifications and learning experiences in English are richer, which is also the inflexible criterion for many colleges or universities to select art major teachers. Unlike other teachers, most bilingual art teachers have overseas study experience, and have absorbed more advanced teaching ideas and methods from the west. Under the background of higher education internationalization and expansion, the international competition in the future will focus on talents and the cultivation of talents. Students should obtain multi-cultural communication ability, promote self-confidence, self-efficiency, inner peace and happiness via bilingual study, in addition to grasp specialized knowledge. As a result, the competency of art teachers is characterized by comprehensiveness, which not only means that the teachers engaging in bilingual teaching should possess comprehensive professional knowledge and skills in bilingual language, but also refers to the evaluation of bilingual teachers' efficiency. The evaluation should set foot on promoting the positive psychological capital of students. To be more specific, art teachers' competency should embody meanings as follows. Firstly, art teachers should acquire high level of English skills and professional competence to be competent in bilingual teaching. Secondly, bilingual teachers should obtain better teaching methods and approaches to make bilingual courses more attractive according to the content of courses and students' characteristics, so as to draw students' attention to earnest study. Finally, art teachers should be able to improve students' English skills and to provide more English communication opportunities and psychological satisfactions like self-confidence, self-efficiency, inner peace and happiness via bilingual teaching. Here below we analyze how to construct bilingual teachers' competency through students' positive psychological capital model.

\section{Mechanism of the Positive Psychological Model for Students}

Luthans (2004) proposed that the competitive edge of enterprises should transform from economic capital, human capital and social capital to psychology capital. Unlike 'What you know' in human capital (Van Marrewijk \& Timmers, 2003) $)^{1}$ and 'Who you know' in social capital (Adler \& Kwon, 2002) ${ }^{2}$, positive psychology capital emphases 'Who you are' and 'Who you can be' (Luthans \& Youssef, 2004) and psychological capital is considered as a positive psychological status that one can develop. It consists of the 
ability to make necessary efforts to fulfill challenging tasks with confidence of success (Efficacy or Confidence), to see positive prospects currently and in the future (Optimism), to stick to the goal and keep improving approaches to achieve success (Hope), and to recover speedily and keep working hard when meeting obstacles (Resilience). To conclude, it consists of four facets, Efficacy, Optimism, Hope and Resilience. The importance of self psychology capital, as competitive edge resources, does not come to light at the very start. With the increasing popularity of positive psychology, more and more people believe that positive qualities and mental attitudes have more potential constructive influence. And psychological capital has traits manageable, moldable, changeable and exploitable (Luthans, et al, 2007). Therefore, more and more organizations commence assessments based on positive psychological capital to study topics like organizational performance and staff training, which is also the starting point of this article. In other words, we can change their state-like characteristics, literally the traits of Hope, Optimism, Efficacy and Resilience, via psychological capital intervention.

Luthans proposed the famous psychological capital intervention model (PCI) in 2007, which stresses that we can improve positive psychological capital via some developing approaches, and eventually influence the organization positively. The specific model is shown as below:

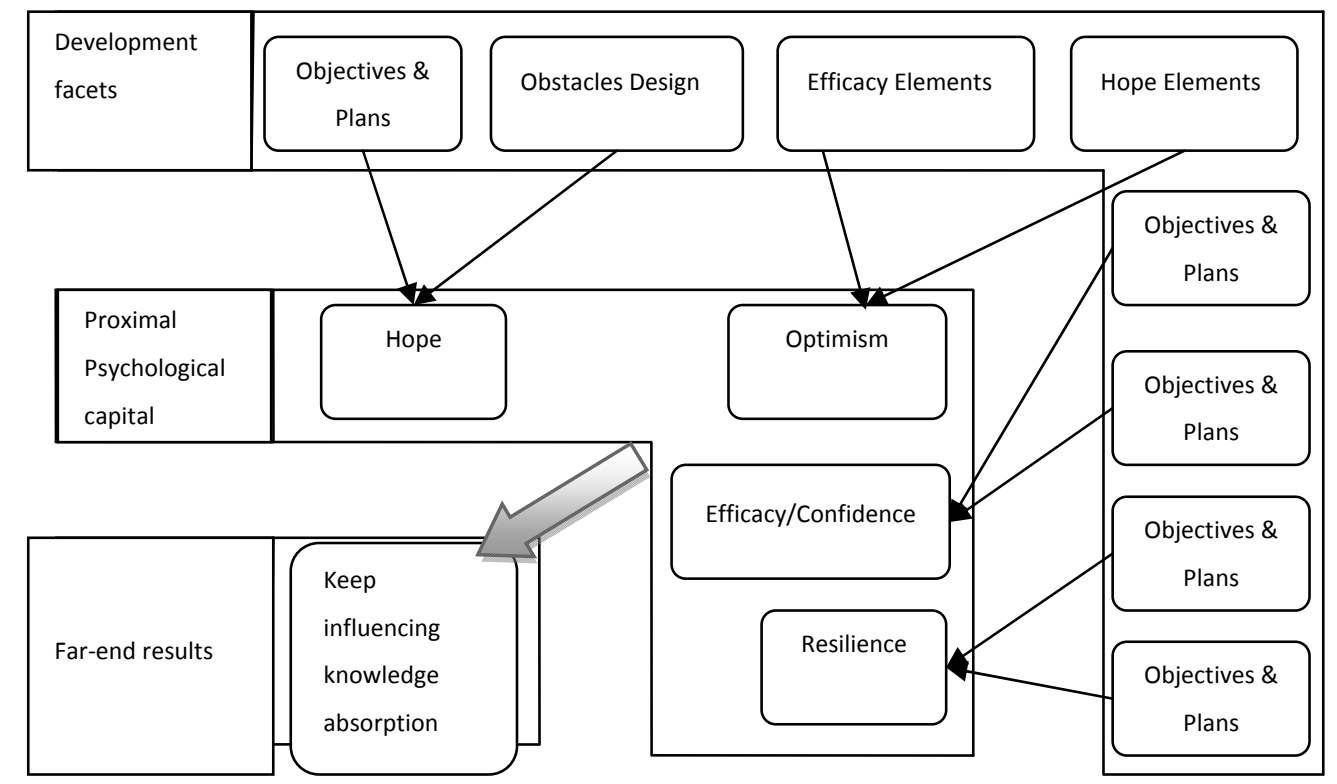

Figure 1. Psychological capital intervention model

Description: This diagram is reorganized according to Luthans, Yousses \& Avoil (2007)

In the process of bilingual teaching, we can keep improving students' positive psychological capital via developing these traits, eventually to improve the competitiveness of higher education. The study of psychological intervention model has important implications in the cultivation of students' psychological capital. However, few scholars have ever studied it by combining it with the bilingual teachers' competency, or discussed how teachers' attitudes and approaches will promote students' positive psychological capital, yet the PCI model's development facets are designed with close relation to the art teachers' teaching attitudes and approaches and the students' motivations. Here below, based on the competency theory, this paper will analyze the competency traits that art teachers should acquire, namely, art teachers' sense of identity with the bilingual teaching, which is also the precondition for nurturing the positive psychological capital of students.

\section{Precondition for Nurturing the Positive Psychological Capital of Students}

Art teachers, as the first-line staff of teaching, are performers of courses and should also be the designers of the courses. As a result, if teachers lack the desire to engage in course design and development, all emphasis from the country, all policy support and all allocated resources will be wasted. Therefore, it is the most urgent thing to find approaches to lead art teachers into participating curriculum design and development. The precondition of 
improving bilingual students' positive psychological capital is to make sure that students and teachers can share the sense of identity and participate in the course together. On the one hand, it can arouse students' sense of identity with the goals of bilingual teaching and a strong desire or active willpower to the bilingual teaching courses so as to improve their learning motivation and make them attend bilingual courses in earnest. On the other hand, teachers share sense of identity with the bilingual teaching goals and display the zeal and expectation to the bilingual teaching practice, so as to adjust the attitude towards bilingual teaching and actively put into more energy to prepare teaching courseware, study different teaching approaches and enhance teaching quality. And students' sense of identity mostly comes from the design of courses by art teachers. Therefore, in this part of work, the teachers' sense of identity is the core.

To identify or to resist are two predictable inter-grown reactions of teachers while they are facing new courses. The former means that they have a tendency to reform courses, and the latter means that they have more concerns on the negative results. But both of these two reactions have positive meanings to the reform of courses. Resistance mood can also empower teachers with authority to plan and develop courses and new teaching approaches. A sense of identification refers to the positive attitude and behavior intention that teachers show in this process. How much teachers concern this topic has been influenced by various factors: art teachers' feelings towards bilingual courses, and their self identification, their involvement in the courses, and the environment related to courses. These will all affect their sense of identification.

In order to enhance their sense of identification, universities and colleges should encourage bilingual teachers to proactively, instead of passively, take part in the development of the faculty and the improvement of teaching, for their attitudes and values will affect the whole teaching process and eventually exert impacts on the achievement of the courses' objectives. Currently, it is urgent to find approaches to increase teachers' interests in participating courses' teaching plan and development. We should process from several aspects below: Firstly, we should increase professional knowledge training of art teachers. For now, most of bilingual teachers have little overseas or training experience. (Statistics in 2009 shows that only $7.5 \%$ of them have received formal training and $13.2 \%$ of them have overseas experience $)^{4}$. Lack of professional abilities leads to their incompetency. At the same time, universities and colleges compel them to adopt bilingual teaching because of the courses settings, which arouses teachers' resistance and dread feelings towards bilingual teaching. As for art teachers, training opportunities are even less. Considering the above, now we should improve communications with other teachers and experts, and make sure they can learn from each other by exchanging views and encourage or inspire each other, therefore teachers can grow together to bring benefit to the teaching practice and acquire sense of achievement to increase their participation. Secondly, the nation's universities and colleges should increase investment and strengthen incentive mechanism. The incentive mechanism at universities is far from ideal, with payment for bilingual courses being 1.5 times that for normal courses ${ }^{5}$. Under this situation, it is hard to ensure art teachers' enthusiasm and participation. In terms of lecture contents and approaches, bilingual courses are more difficult to teach than normal courses, and it is also hard to obtain materials for bilingual courses, so the suggestion is that colleges and universities should increase investment in bilingual teaching. Through increasing bilingual course payment, we can promote bilingual teachers' enthusiasm and initiative. Last, as art teachers are the key to the bilingual teaching, the best way for involving them in the bilingual teaching reform is to make them assume the leader's role, which will convert them from passive participator into proactive leader.

From the above discussion, we know that art teachers' sense of identity with the teaching is the precondition for nurturing the positive psychological capital of students. After discussing the precondition, in what follows, we will discuss the way to cultivate the positive psychological capital of students, that is, a shift from traditional lecturing to exploration of education methods.

\section{Exploration of Education Methods: The Way to Cultivate the Positive Psychological Capital of Students}

Under the traditional lecturing, most of art teachers use original English text books, but only $30 \%$ of them adopt all English teaching in the class, and most of them use PPT in the class. And the teaching approaches are mostly English reading and homework, or lecturing in the class. Teachers give oral lectures of the knowledge and students accept mostly abstract symbols. The traditional teaching has been questioned by many scholars. Teachers also complain that nowadays it gets more and more difficult to satisfy students. The reason lies in that the abstract experience of learning is not as beneficial as the experience of students' personal practice. And the self-exploration teaching approach or other innovative approaches are seldom used in bilingual teaching.

The invention of exploration teaching methods poses challenges to the traditional teaching method. Kolb (1984) ${ }^{6}$ proposed that if students learn from their experiences and group interaction, guided by teachers afterwards, then proceed with introspection to specify abstract concepts and make comparisons, and eventually use their 
experience in the real world, better teaching efficiency can be achieved. The cultivation of positive psychological capital is a type of abstract tacit knowledge, and the better way to acquire tacit knowledge is by instructing it through experience. In the Cone of Learning proposed by Dale (1969), he analyzed the path for generating abstract theory from concrete experience. The specific relation of them is as below:
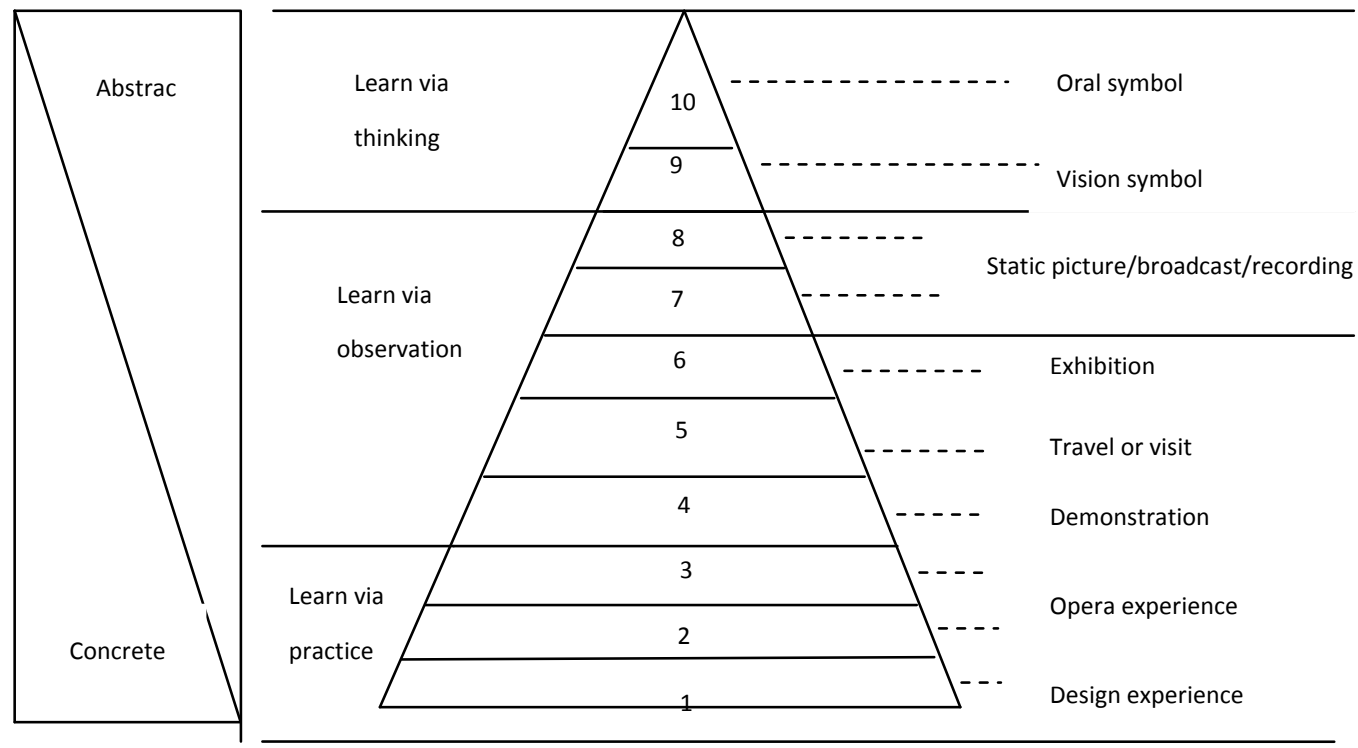

Figure 2. Dale's cone of learning

Description: This diagram is from Dale (1969).

From the diagram, we can see that Dale (1969) divides individual learning experience into 10 layers, and from bottom to top the experience shift from specific to abstract. In addition, learning experience is usually acquired through two approaches, one is direct approach, and the other is indirect approach. Layers 5 to 10 are categorized as passive learning approaches, with the contents that students can acquire from the learning increasing from high levels to lower ones. Layers 1 to 4 belong to proactive learning in which students can usually retain $90 \%$ of the learning in memory, since these kinds of learning place importance on students' experience, feelings and their involvement in the learning process and thus they can generate the best learning result. Layers 1 and 2 are within the exploration of education methods, while layers 9 and 10 are mainly traditional lecturing methods.

Traditional lecturing method refers to that teachers convey knowledge to students via speeches, defining abstract concepts with clear definitions, connecting experience with theoretical knowledge mainly by examples. In this kind of lecturing, teachers cannot provide information in specific circumstances (Brown et al., 1989). In contrast, the self-exploration teaching approach emphasizes the importance of critical thinking and proposes that experience means 'learning via practice'. The core subject of this teaching method is student instead of teacher. It is interactive teaching centering around the teachers' guiding roles and teaching objectives. In order to acquire bilingual knowledge, it is better to combine learning with certain circumstances. The event, atmosphere and culture in the circumstance have great impacts on bilingual teaching. As higher education changes from the elite education to the mass education, bilingual teachers should make sure their overall teaching design is based on the direct experience, then replace experience with diagrams, and eventually reach the abstract stage like word practice so that students can first establish specific experience, then ascend to abstract symbols, and reach practical significance at last.

Specifically, art teachers should set up goals prior to the start in the teaching activities, and find different ways to achieve their goals (objectives and activity plan design); during the activities, through the observation of members within and outside the group, they gain experience from their successful lectures, having a taste of success and the formation of experience and role model; if students encounter trouble, they should give guidance or other alternative tasks to provide more information for the students to try again and arouse the feeling of enlightenment, persuasion and awakenment; they should add culture introduction and fusion through promoting Hope and Efficacy to ensure that students can master the knowledge background systematically on the basis of understanding western culture, acquire abstract knowledge through critical thinking, and then enhance their 
positive psychological capital of Optimism. Eventually, students should rethink profoundly what they lack, and keep trying to obtain techniques, or find ways to avoid risks of further failure from failed experiences of themselves or others so as to establish Resilience. Therefore, students can form their Proximal Psychological Capital, literally, Hope, Optimism, Efficacy and Resilience and Positive Psychological Capital.

\section{Limitations and Prospects}

In addition to the above factors, situational factors of the formation of the positive psychological capital, namely, students' learning motivation and personality also have regulatory function for the formation of psychological capital. Students' learning motivation will certainly affect their abilities to gain positive psychological capital. The teacher will guide students in their own way of learning. Such a learning environment will stimulate students to fulfill their target tasks with confidence. As students are the main participant in the courses, their learning motivation will directly affect how much they can take when facing challenges and difficulties, and students' personality traits can affect their performance in acquiring psychological capital.

Due to the limitation to the length of the paper, here we have not discussed situational factors. The research on art teachers' competency traits for the formation of students' positive psychological capital is a synthetic theory of comprehensive management, sociology and psychology. It is the writer's hope that in the future, more situational factors will be touched upon through empirical research paradigms and, therefore, a comprehensive framework for bilingual teaching will be established.

\section{References}

Adler, P. S., \& Kwon, S. (2002). Social Capital: Prospects for A New Concept. Academy of Management Review, 27, 17-40.

Benchu Zou. (2000). Singing: Shenxiang Singing System Study. Beijing: People's Music Publishing House.

Brown, D. D., Mucci, W. G., Hetzler, R. K., \& Knowlton, R. G. (1989). Cardiovascular and Ventilatory Responses During Formalized T'ai Chi Chuan Exercise. Research Quarterly for Exercise \& Sport, 60, 246-250.

Jinan Sun. (2004). Chinese Modem Music Education Annals (1840-2000). Ji'nan: Shandong Education Press.

Jinyi Guan. (2005). The History of Western Vocal Music Art. Beijing: People's Music Publishing House.

Kolb, D. A. (1984). Experiential Learning: Experience as the Source of Learning and Development. Englewood Cliffs: Prentice-Hall.

Li Cui, \& Li Liang. (2012). The Strategy Research for Higher Education Teachers' Professional Development under the Background of Internationalization. Education Magazine.

Luthans, F., Luthans, K., \& Luthans, B. (2004). Positive Psychological Capital: Going Beyond Human and Social Capital. Business Horizons, 47, 45-50.

Luthans, F., \& Youssef, C. M. (2004). Human, Social, and now Positive Psychological Capital Management. Investing in People for Competitive Advantage. Organiational Dynamics, 33, 321-349.

Luthans, F., \& Youssef, C. M., \& Avolio, B. J. (2007). Psychological Capital: Developing the Human Competitive Edge. Oxford ,UK: Oxford University Press.

Pei Liu. (2003). Ideological Basis and Form of American Music Curriculum and Teaching Material. Chinese Music, $0(1), 27-32$.

Siben, Chen. (2009). Undergraduate Students Reaction to Bilingual Teaching-A Research to a Polytechnic College. Journal of Higher Education Research, 14(3), 83-85.

Songguang Zhao. (2003). Introduction to Psychology of Music Education. Shanghai: Shanghai Music Publishing house.

Van Marrewijk, M., \& Timmers, J. (2003). Human Capital Management: New Possibilities in People Management. Journal of Business Ethics, 44(2), 171-184.

Xiang Shen. (1998). Shen Xiang Vocal Music Teaching Art. Shanghai Music Publishing House, 76.

Xiaoyan, Zhou. (2002).Vocal Music Basis. Beijing: Higher Education Press.

Xincong Liu, \& Zhengfu Liu. (1999). European Vocal Music History. Beijing: China Youth Publishing House.

Yaxian, Ding. (1995). Selection of Vocal Music for Teaching (I). Beijing: People's Music Publishing House. 
Yuejin Chang, \& Li liu. (2009). 'Content-oriented' Teaching Approach and Its Enlightenment to College Bilingual Teaching. Higher Education Press in Jiangsu, 1, 81-83.

Zhenmin, Zhao. (2007). Vocal Music Theory and Teaching. Shanghai: Shanghai Music Publishing House.

Zizheng, Yu. (2003). Reflection of the Singing Origin. People's Music, 12, 37.

\section{Copyrights}

Copyright for this article is retained by the author(s), with first publication rights granted to the journal.

This is an open-access article distributed under the terms and conditions of the Creative Commons Attribution license (http://creativecommons.org/licenses/by/3.0/). 